\section{Management Challenges in a Maturing Industry: A Teaching Case Study of Melon Farming in Latin America}

\author{
Roger A. Hinson ${ }^{1}$, Carl E. Motsenbocker ${ }^{2,3}$, \\ and John V. Westra ${ }^{1}$
}

ADDITIONAL INDEX WORDs. melon imports, competitive strategies, cost leadership, employee relations, diversification, growth markets, mature markets

SUMMARY. This is a horticulture case study of the export market for melons ( Cucumis melo) from Central America to the United States. Melons have provided growers an excellent production and marketing opportunity since the early 1980s. "Offseason" shipments have changed from a consumer novelty to a commodity. The case documents how this producer entered the industry and became a dominant firm using a cost leadership strategy that included adopting advanced production technology and generating large sales volume to take advantage of its opportunity. As the product moved through the cycle from new product to mature market, there were changes in behavior by competing firms, a slowdown in growth of the markets, and reduced profits. Other management practices such as creating profit centers, using employee incentives at all levels, and outsourcing transportation and brokerage services were used to supplement the cost leader strategy. The development of the market and of the firm is documented, providing the basis for discussion of management and marketing issues in courses at the university level in horticulture and agribusiness.

$\mathrm{T}$ his decision case is based on a melon producer-exporter farm in Honduras but the name has been changed for privacy. The company, MelonFarm, was established to produce melons for the U.S. off-season market. Mr. Diego (the founder and general manager of MelonFarm) was interviewed in Honduras to discuss the overall company structure and approach to management. A senior company manager completed a survey instrument that had been created to gather information for case analysis. Follow-up verbal interviews with that manager and Mr. Diego were conducted. MelonFarm provided historical company information that was used in the development of the case study. MelonFarm's principal U.S. broker also was interviewed. The information provided by MelonFarm was not verified through company books or documents such as tax records.

${ }^{1}$ Department of Agricultural Economics and Agribusiness, LSU Agricultural Center, 101 Ag Administration Building, Baton Rouge, LA 70803

${ }^{2}$ Department of Horticulture, LSU Agricultural Center, 137 Julian Miller Hall, Baton Rouge, LA 70803

${ }^{3}$ Corresponding author. E-mail: cmots@lsu.edu.

\section{A brief history of the farm}

The central activity of the Honduran company MelonFarm is melon (muskmelon/cantaloupe and honeydew) and watermelon (Citrullus lanatus) production, but its roots go back to quite different enterprises. Mr. Diego had raised cotton (Gossypium hirsutum) and cattle (Bos taurus) on the Pacific coastal plain. Rising costs of production from increasing pest pressure, the introduction of synthetic fibers, and other factors resulted in the failure of that firm in the late 1970s. Mr. Diego then chose to grow cantaloupe melons on 25 ha of land for the Transnational Chiquita Co. to benefit from the availability of an "off-season" melon market in the United States. At that time, the farm had $\approx 10$ permanent and 100 temporary workers for the production of melons and for a small cattle-breeding operation. By 1983, the farm was experimenting with the export of small quantities of melons to the United States under its own label. The timing was fortuitous. This was the early growth phase in the life cycle of this product (Kohls and Uhl, 2002). The company was savvy enough to take advantage of the rapid growth in its melon business. The agricultural production management skills it had acquired in cotton production provided a solid agronomic base. Technologies to lower production costs of growing and packing melons for export were adopted. MelonFarm has matured into a company with 2900 ha planted to melons, peppers (Capsicum annuum), and sweet corn (Zea mays) with small enterprises in shrimp (Litopenaeus vannamei), tilapia (Oreochromis niloticus), and cattle production (Table 1 ). These enterprises employ the talents and efforts of $\mathbf{5 7 0}$ permanent and $\mathbf{5 0 0 0}$ temporary employees.

Although on the surface the company appears diversified, MelonFarm's business strategy from the beginning has been cost leadership (Porter, 1980). By specializing in melon production, the company has been able to adopt new productivityenhancing technologies, thus lowering unit costs. By 1992, MelonFarm was using drip irrigation and plastic mulch for melon production. Within the next 3 years, drip irrigation was incorporated on all land planted with horticultural crops. Another productivity-enhancing technology adopted in 1994 was "modified atmosphere" in the postharvest phase to extend shelf life. Additional technology changes in other aspects of the company occurred during this timeframe (Table 2).

Perhaps resulting from its experience with cotton production, MelonFarm initiated a program in the late 1980s to mitigate the risk of its single product-single market strategy

\begin{tabular}{llll}
\hline $\begin{array}{l}\text { Units } \\
\text { To convert U.S. to SI, } \\
\text { multiply by }\end{array}$ & U.S. unit & SI unit & $\begin{array}{l}\text { To convert SI to U.S., } \\
\text { multiply by }\end{array}$ \\
\hline 0.4047 & $\mathrm{acre}(\mathrm{s})$ & $\mathrm{ha}$ & 2.4711 \\
45.3592 & $\mathrm{cwt}$ & $\mathrm{kg}$ & 0.0220 \\
0.3048 & $\mathrm{ft}$ & $\mathrm{m}$ & 3.2808 \\
0.4536 & $\mathrm{lb}$ & $\mathrm{kg}$ & 2.2046 \\
0.9072 & $\mathrm{ton}(\mathrm{s})$ & $\mathrm{t}$ & 1.1023
\end{tabular}


Table 1. A description of the resource base for MelonFarm from written documentation provided by the company and personal interviews in 2002.

Land-The company owns more than $90 \%$ of its 2900 ha (7166.1 acres) of cropland. Melon accounted for 2318 ha (5727.9 acres), planted to different varieties, in 2001-2002. In addition, 200 ha (494.2 acres) were planted with jalapeno pepper, 300 ha (741.3 acres) with corn, and 60 ha (148.3 acres) with watermelon seed production. All horticultural production uses drip irrigation and plastic mulch technologies.

Labor-MelonFarm currently has $\approx \mathbf{5 7 0}$ permanent and 5000 temporary employees. A general philosophy of hiring from within is manifest in that $80 \%$ of current management rose through the company ranks. Growth, and expansion into new ventures, led to external hiring when the required expertise and knowledge were not available from within.

Production - In the 2000-2001 season, the company exported nearly $210040-\mathrm{ft}(12.2-\mathrm{m})$ refrigerated containers of melons. The U.S. market received almost $90 \%$ and Europe the remainder. In addition, $4000 \mathrm{lb}$ (1814.4 kg) of watermelon seed, $10 \mathrm{million} \mathrm{lb}$ $(4,535,924 \mathrm{~kg})$ of jalapeno peppers, and $\approx 17,000 \mathrm{cwt}(771,107 \mathrm{~kg})$ of corn were produced.

Transportation-The company contracts with experienced, commercial transportation companies who provide up-to-date and well-maintained equipment, reflecting the importance of maintaining product quality throughout the supply chain.

Marketing-The company has strong relationships with reputable brokerage companies. It believes the "in-house" or owned marketing programs put together by competing companies have not worked well.

Management-There are three profit centers for agricultural products—-melon, peppers, and corn — each with independent management and accounting. Each is expected to be a viable business unit. They are evaluated separately, have unique business plans and organizational structure and resources (cropland, greenhouse space, machinery and equipment, repair shop, meteorological station, office space, packing plants, and precooling warehouses). At the company level, general management handles the export functions and purchasing inputs or supplies. Overhead expenses from general management are charged to individual units pro rata (for example, a deduction for each box of melon produced).

Financial-The company was fortunate to enter production of nontraditional or "off-season" crops early in their product life cycle, when market prices were relatively high and expansion of production had less impact on the market price. Profits from its successful melon enterprise were plowed back into the firm to expand and diversify into new enterprises. Reinvestment into the company has been an underlying philosophy, a low-risk strategy for expansion or diversification that does not expose the company to the demands of creditors.

through diversification. An example was production of white-fleshed honeydew melons in 1989. Five years later, market channels were diversified by exporting muskmelon to Europe. In response to signals from this new market, the company extended its product line by planting other varieties of its basic crops such as 'Mickeylee' watermelon, galia, and 'Piel de Sapo' melon. Transportation and marketing functions always have been outsourced.

Using this approach, MelonFarm has established a 2 -decade history of growth, job creation, and other significant economic impacts in the region.

\section{Melon industry background}

Muskmelon, often called cantaloupe, is the common melon produced and marketed in the United States and North America. Two basic muskmelons are used in commercial trade: 1) the "eastern-type" (often called muskmelon) is sold primarily to local markets and is round with coarse netting, orange flesh, and prominent ribs; and 2) the "westerntype" (often called cantaloupe) is usually shipped to regional and national markets and is small, round, netted, and nonsutured (ribbed) fruit. Muskmelon has reticulate netting on the rind in contrast to "true cantaloupe" that has smooth rinds. These are common in Europe and are sometimes grown in Central America for the European market. Most authorities consider that melon originated in Iran (Persia) or perhaps West Africa and came to the Americas with early explorers and colonists.

Melons are grown in temperate and tropical regions of the world and prefer a hot, dry climate. The United States currently ranks third in production with a $6 \%$ share of the 21.3 million $t$ worldwide production of melons and miscellaneous melons behind China (38\%) and Turkey (9\%) (U.S. Dept. of Agriculture, 2004a). The U.S. production season begins in May, has peak volume in early summer, and continues through December. The U.S. farm gate value for 1999 to 2001 averaged $\approx \$ 320$ million. California led with $60 \%$ of the crop followed by Arizona (17\%) and Texas (14\%) (U.S. Dept. of Agriculture, 2004b).
In the United States, per capita consumption of melons increased 1.7-fold between 1978 and 2004 (U.S. Dept. of Agriculture, 2004c). Consumption increased nearly $60 \%$ from 1980 to 1990 with a $20 \%$ increase in consumption from 1990 to current values. Increased consumption resulted from year-round availability, better production technology, increased consumer health awareness, and adoption of newer varieties.

In the U.S. off-season (November/December to April), almost all the supply is imported. Imports increased dramatically from $10 \%$ of U.S. total melon utilization in the early 1980s to almost one-third in 2004 (Fig. 1). The United States leads with over $40 \%$ of world melon imports or $\approx 680,000 \mathrm{t}$ in 2002 (U.S. Dept. of Agriculture, 2004c). In the late 1970s and early 1980s, entrepreneurs in Central America and Mexico perceived the demand for off-season melon and developed and adopted new technologies for production, postharvest handling, and transportation. These exporters steadily increased production, and by 1997, Mexico was the leading melon exporter to 
Table 2. A summary of significant events that affected MelonFarm was provided in written documentation and personal interviews in 2002.
1989-1990 to 1996-1997
- Produced white honeydew melon
- Exported muskmelon to Europe
- Diversified into pond shrimp production
- Upgraded to drip irrigation system-plastic mulch technology
- Added modified atmosphere technology
- Added 'Mickylee' watermelons, galia, and 'Piel de Sapo' melons for the European market
- Introduced "total quality" concept
- Diversified into cattle breeding and tilapia production
- Exported seedless watermelon to Europe
1997-1998
- Implemented "process improvement" concepts
- Expanded "Packing and Production Technique Guide"
- Initiated watermelon seed production
- Used "modified atmosphere" technology for muskmelon exported to the United States

\section{8-1999}
- Suffered substantial economic damage as a result of flooding from Hurricane Mitch. Facilities and machinery were washed away; production activities were disrupted; and farmland experienced major change (erosion in some areas, substantial siltation in others)

1999-2000

- Diversified production into leather leaf fern (Rumobra adiantiformis) for export to Europe and hardwoods

- Established "Quality Control and Process" department

2000-2001

- Achieved AgriSafe certification

- Enhanced fertigation technology

- Diversified production of muskmelon varieties

- Produced jalapeno pepper for export to United States

- Consolidated "modified atmosphere" technology in muskmelon

2001-2002

- Improved fertigation technology

- Introduced integrated pest management production strategies

- Developed a formal program to investigate postharvest problems

- Initiated "Social Projection Program" for lower-level employees

- Applied for "EUREPGAP" certification ${ }^{z}$

- Exported muskmelon to Mexico

- Diversified into asparagus (Asparagus officinalis)

2002-2003

- Improved packing facilities

- Complete implementation of "Social Projection Program"

- Applied for ISO $14,000^{\mathrm{y}}$ (environmental stewardship) certification

${ }^{2}$ EUREPGAP was an initiative of retailers belonging to the Euro-Retailer Produce Working Group and evolved to a partnership of producers and retailers working to develop accepted standards and procedures for certification of good agricultural practices (EUREPGAP, 2006).

International Standards Organization (ISO) established standards on good environmental practices that can be applied pragmatically by all organizations (ISO, 2006).

the United States with approximately one-third of the total volume (Fig. 2). Melon exports from Mexico peaked in 1999 and then dramatically decreased through 2003. As measured by volume, the leading exporters to the United States in 2004 were Guatemala, Costa Rica, Honduras,
Dominican Republic, and Mexico in decreasing order (U.S. Dept. of Agriculture, 2004f). From 1997 to 2003 , the melon volume exported to the United States from Costa Rica increased 2.5-fold, whereas Guatemala had a $50 \%$ increase and Honduras' exports changed relatively little.
Among other factors, melon exporters and the changing import shares are affected by weather. In late Oct. 1998, the catastrophic impact of Hurricane Mitch was absorbed by Honduras in particular and to a lesser extent by other Central American countries. The melon industry in Honduras was severely affected. Many melon producer-exporter companies suffered major economic damage from flooding as facilities and machinery were washed away or destroyed. Production activities were disrupted. Farmland experienced major change such as erosion in some areas and siltation in others. Several Honduran melon producers were unable to overcome the financial strains in the aftermath of the hurricane.

\section{The changing business environment Markets, prices, and competitors}

Over the past 25 years, melon markets have changed significantly. Initially, the market for melons was expanding because the demand for off-season melons was growing. However, what began as a novelty became a commodity. In the early 1980s, these products were being supplied to the U.S. market in small quantities. Demand exceeded supply, prices rose, and the associated profits attracted other companies to the industry. Production area expanded, supply increased, and the quantity of melons supplied to the market eventually caught up with demand. As the market reached maturity (mostly repeat buyers rather than a combination of new and repeat buyers), the growth rate slowed and growers felt impacts of lower prices on profitability. By the early 1990s, many significantsized players in the industry (but not necessarily low-cost growers) were gone. However, the quantity of melons available in the market was not reduced because the more efficient farms consolidated the industry.

As a result of these market forces, approximately six Latin American companies now compete for the northern hemisphere's off-season market. Given this situation, MelonFarm's business plan assumes that, in a commodity market, it cannot expect selling prices to improve. It assumes, in fact, that market prices could decline further as existing companies expand production. MelonFarm 


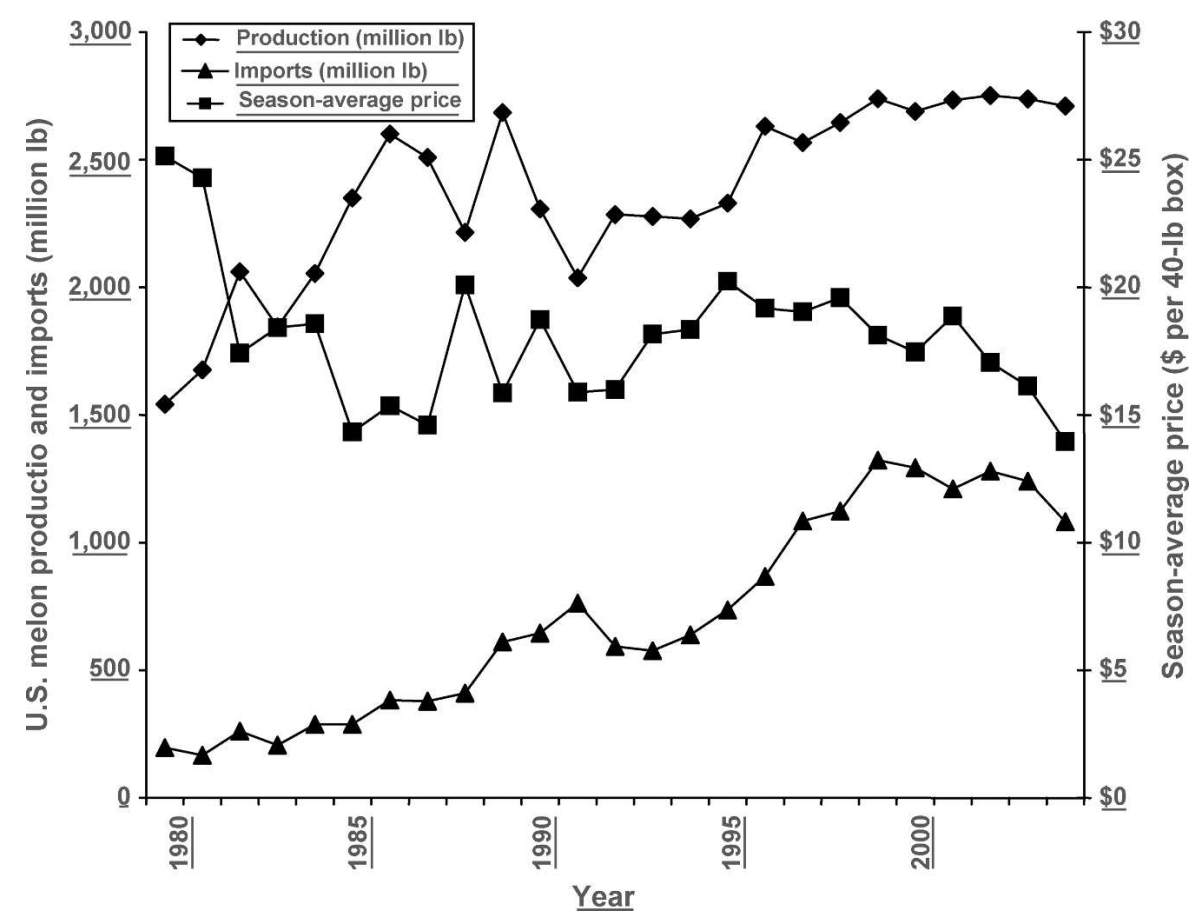

Fig. 1. Season-average price of melons (muskmelon and honeydew) reported in constant year 2000 dollars, annual quantity produced in the United States, and annual quantity imported into the United States from 1980 to 2004 (U.S. Dept. of Agriculture, 2004d). Production data from 1982 to 1991 was estimated by the U.S. Dept. of Agriculture based on available state data adjusted to the national level $(1 \mathrm{lb}=0.4536 \mathrm{~kg}$, $\$ 1$ per $40-\mathrm{lb}$ box $=\$ 0.0551 \cdot \mathrm{kg})$.

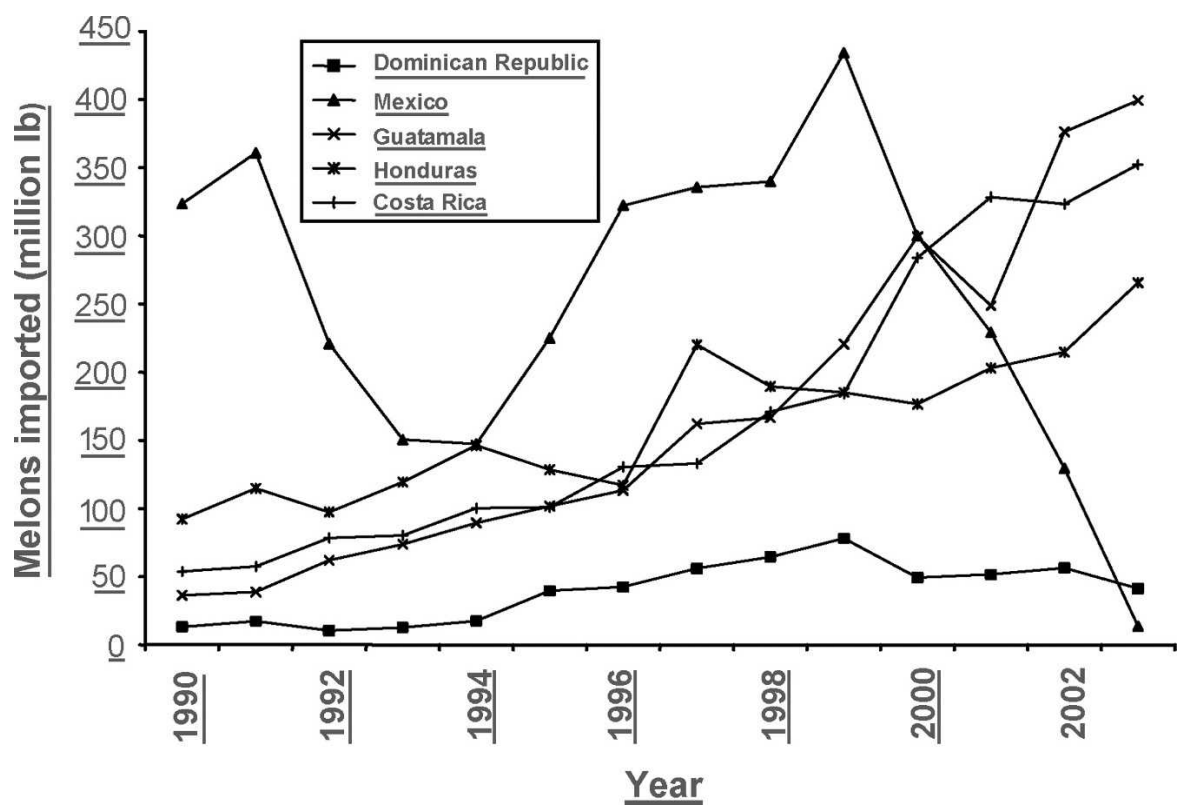

Fig. 2. Annual quantity of fresh-market melons imported into the United States from major exporting countries from 1990 to 2004, reported in millions of pounds (U.S. Dept. of Agriculture, 2004e) $(1 \mathrm{lb}=0.4536 \mathrm{~kg})$.

also is familiar enough with its competitors' general production plans to feel confident that anticipated production levels will prevent price increases. In fact, real prices for melons have declined from 1980 to 2004 (Fig. 2) while nominal prices stagnated.

MelonFarm stated that a competitive company must be large enough to achieve economies of size and provide competitive quality on a consistent basis to maintain its customer base (Porter, 1980). It has not increased the amount of land in production. Instead, it instituted two sets of actions designed to hold its market share and price: 1) improving yields through better technical processes and achieving reduced unit costs (a continuing philosophy), and the estimated costs by category are shown in Table 3 ; and 2 ) maintaining price by providing higher product quality and adding services such as special packaging. MelonFarm believes these attributes should make a difference to buyers as they consider the various product offers.

The strategy, then, is to control costs, sell to a variety of kinds of customers and channels, and to rely on value-adding services to provide acceptable margins and help assure that price does not fall below some critical level.

The product life cycles in the United States and European market have been similar. When Europe's melon supply came solely from Spain, Central American melons were a novel product. Now that suppliers from Brazil, the Middle East, and Africa, as well as Central America, compete in that market, MelonFarm is analyzing how to position its product in that market so sales are profitable even if lower prices occur. The European melon market is just as competitive as the U.S. market with various countries producing a similar product for the off-season market. Melon producers in Central America have many factors to consider when competing in Europe. The European market has more diversity in the melons that are in demand (such as galia, 'Piel de Sapo', 'Charentais', and 'Juane Canary') compared with the standard muskmelon that is grown for the U.S. market. Greater shipping distances from this region, compared with Africa and the Middle East, result in higher transport costs and potentially higher investment risk. In addition, longer transit times lead to lower potential shelf life and decreased product quality at the market. Postharvest technology such as controlled atmosphere during transport tends to negate lower shelf life while increasing costs. These are some of the factors that shippers need to consider when attempting to export melon from Central America to Europe. 
Table 3. Estimated cost of production, packing, administration, and transportation for melons that were produced in Honduras and exported to the U.S. market. ${ }^{z}$

$\operatorname{Cost}(\$ / h a)^{y}$

Production costs

Wages and salaries

Seed

49

Fertilizer

107

Chemicals

199

Plastic

145

Field operations

118

Total production costs

686

Wages and salaries

Packing costs

Boxes

41

411

Packing materials

Packing chemicals

Pallets

Other materials

Total packing costs

Administration

Administration and financial costs

Financial

Total administration costs

In-country transportation costs

In-country transportation

Port fees

Total in-country transportation costs

Transportation costs to the United States

Maritime shipping

Broker's commission

Cold storage and handling

Port fees

Total international transportation costs

Total costs of production and transportation

4,413

${ }^{2}$ Data based on a production area of 70 ha (173.0 acres) (O. Zapata, personal communication, 2 Jan. 2002).

${ }^{\mathrm{y}}$ Costs in U.S. dollars based on the conversion $\$ 1=18.8$ Honduran Lempira; $\$ 1.00 \cdot \mathrm{ha}=\$ 0.4047 \cdot$ acre.

There have been significant changes in consumers' expectations of product characteristics in the 1980s and 1990s. Consumers demand, and retailers supply, a high-quality product without blemishes. In the United States, muskmelon and honeydew remain dominant in a little-changed product line. The European product line, however, now contains diverse products such as the sweeter galia and 'Piel de Sapo' melons. Also, consumers now prefer larger-sized melons. The standard has increased from $\approx 2.5$ to 3 $\mathrm{lb}$ each (packed 15 fruit.box weighing 40 to $45 \mathrm{lb}$ ) to $\approx 4.5 \mathrm{lb}$ each (packed 9 fruit-box). In response to these changes in consumer preferences, producers have adopted new technologies or production techniques and added new varieties to their operations.

MelonFarm has developed a variety of products for the market according to management and one of its
U.S. brokers. An example was the "perfect melon" program designed to enhance the perception of quality through uniformity. This proved difficult to accomplish consistently. Many shipments within this program met the high criteria, whereas others did not. Without assurance that the criteria would be met consistently, the higher price was not sustained. On the other hand, MelonFarm did succeed in implementing some very specific customer requests. Two examples illustrate this responsiveness: 1) Harvest, packing, and shipment take place every day of the week. Shipments are spread more evenly through time and supply chain efficiency is improved. 2) At the request of a mass merchandiser customer, a three-pack mesh sleeve of 3-lb melons was packaged. The permitted weight variance between melons was very small, and the melons were expected to be similar in appearance. The company has been able to supply this product consistently.

Other examples also are cited (Table 2).

\section{Food safety and the regulatory process}

Another factor that changed was the regulatory environment in both the United States and Europe. The regulatory process strengthened over time, and MelonFarm noted more inspections and more product detentions. In European markets, the food retail industry developed guidelines to be met by all companies supplying product to those markets. This EUREPGAP initiative was in response to "demands of consumers, retailers, and their global suppliers to create and implement a series of sector specific farm certification standards...to ensure integrity, transparency, and harmonization of global agricultural standards...including requirements for safe food that is produced respecting worker health, safety and welfare, environmental and animal welfare issues" (EUREPGAP, 2006). In addition, MelonFarm received International Standards Organization (ISO) 14,000 certification, verifying its efforts to address environmental issues. The ISO addresses farm environmental issues by promoting "a series of international, voluntary environmental management standards...that effectively address the needs of organizations worldwide by providing a common framework for managing environmental issues" (International Standards Organization, 2006). MelonFarm also received AgriSafe certification in 2002 as verification of commitment to agricultural occupational health and safety of its employees (AgriSafe Network, Inc., 2006). Integrated pest management (IPM) programs also were put in place. Although not a regulatory requirement, IPM offers production cost savings and the advantages of reduced residues. MelonFarm felt that its aggressive integration of these programs provided another source of competitive advantage.

\section{Exporting and selling}

MelonFarm's product is sold in the United States and Europe by a small group of brokers. Some competing producers established "sister" 
companies in the destination country to perform marketing and selling activities. In contrast, MelonFarm has focused on production cost leadership and has hired marketing and transportation companies to provide needed services. The premise is that specialized companies have a knowledge and experience base that allows them to provide services more efficiently. MelonFarm's relationships with these companies have been longlasting, and they are regarded as partners. The brokerage companies serve as the receiver at the import site, performing required functions such as customs, freight forwarding, and warehousing, and they arrange shipping to the final customer (Kohls and Uhl, 2002). Other services include invoicing the customer, receiving payments, ocean freight, customs clearance, handling, and in-and-out warehousing. Broker companies receive a sales commission and are paid for the other services they provide.

A significant set of activities, then, is performed outside MelonFarm. Its own "in-house" selling costs include coordination, distribution, review, and accounting costs. In contrast, most competitors own companies in destination countries that receive and market their product. They also may own transportation gear for hauling product to the port. MelonFarm feels that services received and rates charged by its brokers and transportation providers are equivalent to those its competitors generate through internal activities. The advantage to MelonFarm is that few company resources are devoted to marketing. Those resources are available to support technology adoption and cost leadership goals.

This selling arrangement is convenient but does leave room for concern about the quality and quantity of market feedback signals from the consumer. Brokers have the primary relationship with retailer and foodservice customers. They relay information about customer preferences and concerns. They are, however, another intermediary in the chain and represent another possibility that consumers' messages are not clearly transmitted. If there is a lag in the time in which the company understands changes in consumers' product preferences, the appropriate response also is delayed. To supplement brokers' opinions, MelonFarm representatives attend trade shows to maintain contacts with customers. During the shipping season, a company representative is assigned to each import site to assure customer service. With on-site company representation, MelonFarm stated that it can respond quickly to problems such as load rejections. The company also has programs to address the needs of specific customers. At times, items are packed and labeled to meet specific customer orders (with the buyer's brand, for example). Own-brand melons are shipped to the European market. Promotion of that brand is handled by brokers and retailers through pointof-purchase activities such as flyers.

\section{Summary of business strategy}

Since its inception, the company's core strategy in melon production has been to adopt production technologies that increase output and lower unit production costs, providing cost leadership. To this end, its financial and intellectual resources are applied to finding technologies that increase its efficiency. It was an early adopter of computerized drip irrigation systems under plastic mulch to deliver water and fertilizer (fertigation) and seeks to be as technologically efficient and productive as firms in developed countries.

Even with a basic strategy of cost leadership in a commodity market, competitive levels of quality and service are "table stakes" to compete in the industry. The productivity-enhancing technologies make the product quality expectations attainable.

\section{Some self-identified critical events and issues}

Tax incentive. A government incentive has exempted the company from taxes on profit. This incentive remains an important contributing factor to its survival and competitiveness.

Regulatory-food safety issues. Although it did not seem so at the time, the firm stated it was positively affected by enhanced regulatory policies affecting food safety during the Clinton administration. Programs that made the company stronger and more competitive were implemented. These programs, as described previously, include AgriSafe for residues and microorganisms, standards and compliance verification issues associated with EUREPGAP, and ISO certification. The company feels that a workable program in this area would be a technological breakthrough and is working with a Mexican company to reduce pesticide use.

Productivity increases are important. MelonFarm has heard rumors that a Mexican company has achieved yields up to 2000 boxes/ha and managed pests efficiently. In contrast, MelonFarm averages $\approx 1300$ boxes/ha and a top competitor averages $\approx 1400$ boxes/ha.

EMPLOYEe RELATIONSHIPS. Melon Farm feels that its employee compensation and retention structure provide a significant advantage over competitors through the goal of establishing and retaining its workforce, and that a motivated and loyal workforce can be an effective method of increasing efficiency and productivity, improving technical processes and reducing cost. For example: 1) There is a longstanding profit-sharing program. 2) Job expectations are described and structured. The quantity of work (measured against a scale) and the quality of the completed work are measured and evaluated. Employee compensation is linked to these metrics of job performance. 3 ) Profit centers exist, and business unit managers receive fixed salaries and incentive compensation based on unit results.

An incentive program rewards employees who identify more effective procedures. Another incentive rewards long-term employees with a profit-sharing program. Importantly, these productivity factors are within the firm's control. The company notes it is unaware of other companies in Honduras with a comparable program. As evidence of the success of its program, few employees voluntarily leave the company. The broker interview generally corroborated that view.

RISK MANAGEMENT AND DIVERSIFICATION. The company grew from $\approx \$ 100,000$ in gross sales in 1980 to $\approx \$ 28$ million in 2002 . Because $90 \%$ of total revenue still results from melon sales, there is a perception that additional risk mitigation is needed. The company has identified additional lines of business that appear to have profit potential, and resources have been added in these areas. Risk is managed by 
distributing investments among these different enterprises and the alternative products and markets activities described previously.

Attitude toward change. Management identified its openness to change as a major success factor. From a philosophy that nothing is static, new opportunities can be identified in production technology, new varieties that appear from research, changing consumer preferences, and the expectations of retail and foodservice companies. The approach has been to innovate when opportunities appeared, and MelonFarm feels that it must look forward and anticipate change. It must be ahead of the change rate of its competitors.

\section{Case questions}

Although this case does not end at a crossroads where Mr. Diego must make critical decisions, alternative strategies always were available to the firm. MelonFarm chose to be a high-volume cost leader. The alternative generic strategies of differentiation and focus might have been profitable at another sales level. In the phases of the product life cycle, it might have been appropriate to switch between strategies. For example, differentiation could have been followed by a transition to the cost leader strategy. Another alternative might have been to change the company's production methods and grading standards, increase its emphasis on specialty melons, and adapt its strategy as the market matured to a more commodity-oriented product. Therefore, the path taken, of specialization in melons, investment in technology to achieve cost leadership, and large volumes of product sold into the market to get low cost, provided a competitive advantage. However, given the nature of this market, management may need to revisit this business strategy. Instructors and students may want to consider those alternatives that were not pursued and discuss their implications. Please consider the questions subsequently to explore these ideas.

1. The impacts of Hurricane Mitch in 1998 revealed that concentrated melon production is risky and suggested that additional diversification might be appropriate. What are some alternatives to melon produc- tion that this firm might consider, and what are their advantages and disadvantages?

2. Because this firm has focused on cost leadership throughout its history, it needs information on the latest cost-reducing technologies. What can MelonFarm do to be sure it has the latest information on costreducing technology in melon production?

3. Cost leadership has been this firm's core strategy and it has been quite successful. Imagine you are a consultant retained by MelonFarm to help develop a strategic plan for the next 5 to 10 years. What additional information would you need for such an assignment? Where might you find this information?

4. Diversification is often suggested as a means of reducing risk for a firm. Which crops might help this firm reduce its revenue risk (reduced revenue variance)? Are those crops complementary to melons (such that these crops might use the same machinery or use labor in other seasons when it is less used, and so on)?

5. The choice of specialization in production and the cost leadership strategy seem to have served MelonFarm well. However, as this firm grows, should it consider expanding into other segments of the vertical supply chain such as establishing a marketing company in the United States or investing in transportation services? How has the maturing melon industry altered its strategy of specialization?

6. MelonFarm's brokers provide a range of services, including collection of market information, changes in customer and consumer preferences, and other information relevant to marketing and selling. What "value" do these brokers have to MelonFarm? What services do they provide that MelonFarm might assume, if it so desired? What might MelonFarm have to forego to assume some of the services provided by its brokers? What might be the benefits?

7. MelonFarm's approach to labor relations - trying to maintain a stable, trained, and dependable labor force-seems to differ from the approach taken by most of its competitors. Did you see outcomes in the discussion of the case that suggest these policies have paid off for the company? What other actions might the company take to provide additional incentive to the workforce to retain the dependability that has been established?

\section{Literature cited}

AgriSafe Network, Inc. 2006. Preventive healthcare for the farming community. 18 Sept. 2006. <http://www.agrisafe.org/ farmers.php $>$.

EUREPGAP. 2006. The global partnership for safe and sustainable agriculture. 18 Sept. 2006. <http://www.eurepgap. org/Languages/English/index_html>.

International Standards Organization. 2006. Frequently asked questions. 19 Sept. 2006. <http://www.tc207.org/ faq.asp? Question=2>.

Kohls, R.L. and J.N. Uhl. 2002. Marketing of agricultural products. 9th ed. Prentice-Hall, Upper Saddle River, N.J.

Porter, M. 1980. Competitive strategy. Free Press, N.Y.

U.S. Dept of Agriculture. 2004a. Table 32-World cantaloupes and other melons: Production, 1990-2003. 12 Jan. 2004. <http://usda.mannlib.cornell. edu/data-sets / specialty/02002/ wrldprod.xls $>$.

U.S. Dept. of Agriculture. 2004b. Tables $2,3,4$, and 15. U.S. and states (AZ, CA, TX): Acreage, yield, production, and value, 1960-2003. 12 Jan. 2004. <http://usda.mannlib.cornell.edu/data-sets/specialty/ 02002/USAcrPrd.xls, AZAcrPrd.xls, CAAcrPrd.xls, TXAcrPrd.xls>.

U.S. Dept. of Agriculture. 2004c. Table 36-World cantaloupes and other melons: Import volume, 1990-2002. 12 Jan. 2004. <http://usda.mannlib.cornell. edu/data-sets / specialty/02002/ wrldcntimpvol.xls $>$.

U.S. Dept. of Agriculture. 2004d. Table 1-U.S. cantaloupe: Supply, utilization, and price, farm weight, 1970-2004. 24 Aug. 2005. <http://usda.mannlib. cornell.edu/data-sets/specialty/02002/ usupuse.xls $>$.

U.S. Dept. of Agriculture. 2004e. Table 39-U.S. fresh-market cantaloupe: Monthly import volume by country, 1997-2004. 12 Jan. 2004. <http://usda. mannlib.cornell.edu/data-sets/specialty/ 02002/moimpvol.xls>.

U.S. Dept. of Agriculture. 2004f. Table 26-U.S. cantaloupe: Fresh-market import volume from selected countries, 19902003. 24 Aug. 2005. <http://usda. mannlib.cornell.edu/data-sets/specialty/ 02002/imprtvol.xls>. 